\title{
Photochemical approach to functionalized benzobicyclo[3.2.1]octene structures via fused oxazoline derivatives from 4- and 5-(o-vinylstyryl)oxazoles
}

\author{
Ivana Šagud ${ }^{1}$, Simona Božić ${ }^{1}$, Željko Marinić ${ }^{2}$ and Marija Šindler-Kulyk ${ }^{* 1}$
}

\author{
Full Research Paper \\ Address: \\ ${ }^{1}$ Department of Organic Chemistry, Faculty of Chemical Engineering \\ and Technology, University of Zagreb, Marulićev trg 19, 10000 \\ Zagreb, Croatia and ${ }^{2}$ NMR Center, Rudjer Bošković Institute, \\ Bijenička cesta 54, 10000 Zagreb, Croatia \\ Email: \\ Marija Šindler-Kulyk - marija.sindler@fkit.hr \\ * Corresponding author \\ Keywords: \\ bicyclo[3.2.1]octane; intramolecular photocycloaddition; oxazole; \\ styryl; vinyl
}

Open Access

\author{
Beilstein J. Org. Chem. 2014, 10, 2222-2229. \\ doi:10.3762/bjoc. 10.230 \\ Received: 11 July 2014 \\ Accepted: 04 September 2014 \\ Published: 18 September 2014 \\ Dedicated to Professor Wim Laarhoven on the occasion of his 90th \\ birthday. \\ Associate Editor: C. Stephenson \\ (C) 2014 Šagud et al; licensee Beilstein-Institut. \\ License and terms: see end of document.
}

\begin{abstract}
Novel cis/trans-4- and cis/trans-5-(2-vinylstyryl)oxazoles have been synthesized by Wittig reactions from the diphosphonium salt of $\alpha, \alpha^{\prime}-o$-xylene dibromide, formaldehyde and 4- and 5-oxazolecarbaldehydes, respectively. In contrast, trans-5-(2vinylstyryl)oxazole has been synthesized by the van Leusen reaction from trans-3-(2-vinylphenyl)acrylaldehyde which is prepared from $o$-vinylbenzaldehyde and (formylmethylene)triphenylphosphorane. The 4- and 5-(2-vinylstyryl)oxazoles afford, by photochemical intramolecular cycloaddition, diverse fused oxazoline-benzobicyclo[3.2.1] octadienes, which are identified and characterized by spectroscopic methods. The photoproducts formed are relatively unstable and spontaneously or on silica gel undergo oxazoline ring opening followed by formation of formiato- or formamido-benzobicyclo[3.2.1] octenone derivatives. On irradiation of 4-(2-vinylstyryl)oxazole small quantities of electrocyclization product, 4-(1,2-dihydronaphthalen-2-yl)oxazole, are isolated and spectroscopically characterized.
\end{abstract}

\section{Introduction}

The bicyclo[3.2.1] octane skeleton is the basic framework of numerous important biologically active natural compounds or their metabolites [1]. Properly functionalized bicyclo[3.2.1]octanes have proved as useful reactive intermediates in stereoselective transformations making these derivatives powerful building blocks in organic synthetic strategies [2]. Various methodologies and new synthetic approaches for their preparation and reactivity have been reviewed [3]. Continuing our long-standing interest for photochemical intramolecular cycloaddition reactions of various $\beta$-heteroaryl- $o$-divinylbenzenes, furans [4-6], thiophenes [6-8], pyroles $[9,10]$ and sydnones [11$13]$, as routes to polycyclic compounds, we turned our attention 
to oxazole derivatives. The oxazole structure is commonly found in natural products and pharmaceuticals [14-17] and is applied in useful reagents and intermediates in organic synthesis [18-25]. There are examples of oxazole photochemical intermolecular cycloadditions [26-32], but to the best of our knowledge, there are no examples of intramolecular photocycloaddition. We describe herein, the synthesis of new 4- and 5-(2-vinylstyryl)oxazoles $(\mathbf{1}, \mathbf{2})$ and their intramolecular photocycloaddition to diverse fused tetracyclic oxazoline compounds which further spontaneously or during the work-up procedure hydrolyze to benzobicyclo[3.2.1] octenone derivatives. This is a new method for the synthesis of functionalized benzobicyclo[3.2.1] octenes.

\section{Results and Discussion}

cis/trans-Isomers of 4- and 5-oxazole derivatives $(\mathbf{1}, \mathbf{2})$ were synthesized by Wittig reactions from the diphosphonium salt of $\alpha, \alpha$ - $o$-xylene dibromide, formaldehyde and oxazole- 4 - and 5 -carbaldehydes $(3,4)$, respectively, in absolute ethanol with sodium ethoxide as a base (Scheme 1).

The procedure of this multicomponent reaction is slightly modified, compared to the described method [33], in order to optimize the yields. The yield of 4-oxazole derivative 1 was $50 \%$ whereas the best result found for the 5-oxazole derivative $\mathbf{2}$ was $22 \%$. The required oxazole-4/5-carbaldehydes $(3,4)$ [34-36] were prepared from commercially available esters by DIBALH reduction following the procedure [34] for oxazole-4-carbaldehyde (3). The crude products obtained were used in the next step of the synthesis without purification because of their volatility. Reduction of ethyl oxazole-4-carboxylate proceeds completely whereas the crude reaction sample of the oxazole-5carbaldehyde (4) contains $10 \%$ of unreacted ester. The unreacted ester is difficult to separate by column chromatography from the trans-isomer 2 . It could be removed from the reaction mixture by mild basic hydrolysis [37].

To avoid the use of volatile oxazole-5-carbaldehyde (4) we developed a new synthetic route to 5-(2-vinylstyryl)oxazole (2) in which the oxazole ring is formed at the end of the reaction sequence (Scheme 1). An oxazole ring substituted in the 5-position can be synthesized from the corresponding aldehydes using van Leusen's reagent, tosyl methyl isocyanide (TosMIC) $[38,39]$. For the preparation of 5-(2-vinylstyryl)oxazole (2) by this method 3-(2-vinylphenyl)acrylaldehyde (6) was needed. This new $o$-substituted phenylacrylaldehyde 6 was prepared using (formylmethylene)triphenylphosphorane by a Wittig reaction from $o$-vinylbenzaldehyde (5). The yield of desired product $\mathbf{6}$ is lower, compared to the yields of previously prepared $\beta$-heteroarylacrylaldehydes [23]. This can be explained by the diminished nucleophilic attack of the reagent to the carbonyl moiety due to the steric hindrance of the $o$-vinyl group in 5 and continued competitive reaction of the carbonyl from the formed $o$-vinylphenylacrylaldehyde $\mathbf{6}$ with (formylmethylene)triphenylphosphorane to give 5-(2-vinylphenyl)penta-2,4-dienal (7) as byproduct. Under optimal reaction conditions (see Supporting Information File 1) 32\% trans3-(2-vinylphenyl)prop-2-enal (6) is obtained in addition with 5\% trans,trans-5-(2-vinylphenyl)penta-2,4-dienal (7) as a contaminant, alongside with a large amount of resinous material. The required $o$-vinylbenzaldehyde (5) [40] was synthesized from 2-bromostyrene and used without purification. As the starting aldehyde 6 for the reaction with TosMIC was in trans configuration the 5-(2-vinylstyryl)oxazole (2) obtained retained the trans configuration. This is clearly seen from the coupling constants of the ethylene protons $(J=16 \mathrm{~Hz})$ in the ${ }^{1} \mathrm{H}$ NMR. All new compounds for further experiments, cis/trans-1, cis/ trans-2 and trans-6 are isolated by column chromatography on

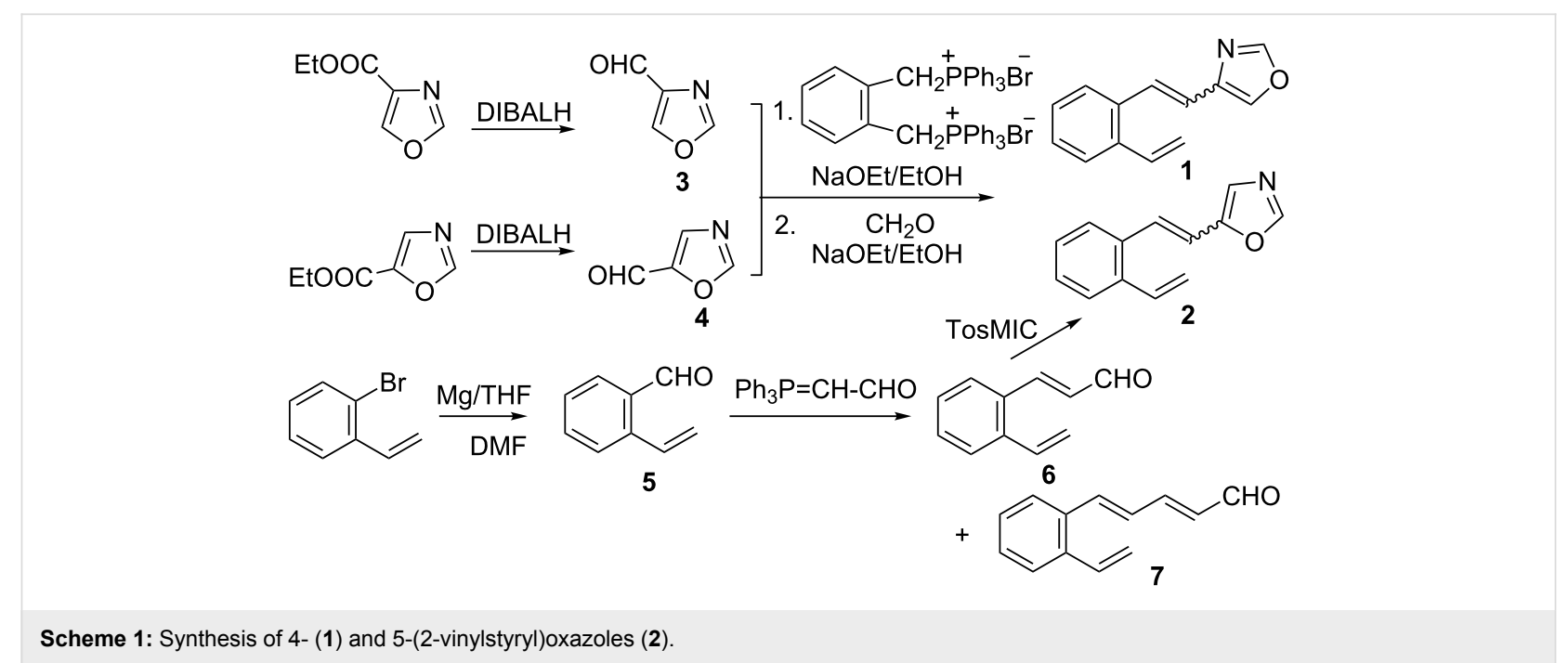


silica gel in moderate yields (22-50\%) and characterized by spectroscopic methods (see Supporting Information File 1).

The irradiation experiments have been performed in a Rayonet reactor (>300 nm, rt, using up to 16 lamps each with a power of $8 \mathrm{~W}$ ) with petroleum ether, acetonitrile or benzene as a solvent Benzene gave the cleanest reaction profile and was used as the solvent in further preparative experiments. The ${ }^{1} \mathrm{H}$ NMR spectra of the crude photomixtures showed complete conversion after 3-5 hours of irradiation. In the case of cis/trans-4-(2vinylstyryl)oxazoles $\mathbf{1}$ two dominant products $\mathbf{8 a}$ (74\%) and $\mathbf{8 b}$ $(20 \%)$ were observed in the ${ }^{1} \mathrm{H}$ NMR spectra and a small quantity of $9(6 \%)$ was observed as well (Scheme 2$)$.
Whereas in the case of cis/trans-5-(2-vinylstyryl)oxazoles (2) one major product $10(75 \%)$ and minor product 11 (25\%) along with a lot of small quantities of unidentified side products (Scheme 2) were observed. Irradiation of compounds $\mathbf{1}$ and $\mathbf{2}$ in NMR tubes dissolved in deuterated benzene and recording the spectra at timed intervals demonstrated that $\mathbf{1 1}$ is not the photochemical product as can be clearly seen in Figure 1.

After complete conversion of the starting compound $\mathbf{2}$ only compound 10 was present in the ${ }^{1} \mathrm{H}$ NMR spectrum in contrast to photochemical conversion of compound $\mathbf{1}$ in which the same mixture of three products $(\mathbf{8 a}, \mathbf{8 b}$ and $\mathbf{9})$ is obtained as in preparative experiments.<smiles>C=Cc1ccccc1/C=C/[14c]1cocn1</smiles>

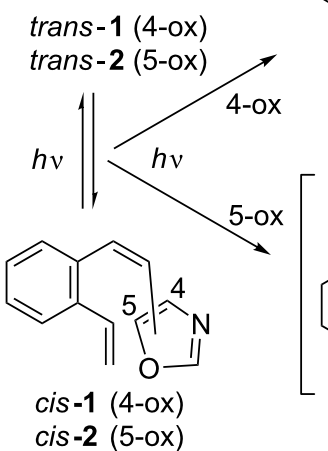

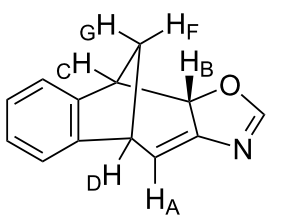

$r e /-(2 S)-8 a$

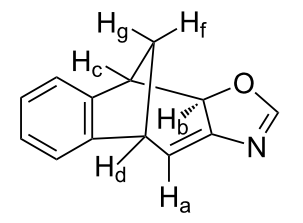

$r e l-(2 R)-8 b$<smiles></smiles>

9

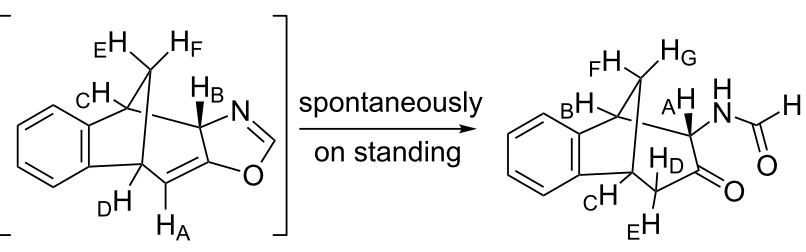

rel-(2S)-10

Scheme 2: Irradiation of 4- (1) and 5-(2-vinylstyryl)oxazoles (2) (crude reaction mixtures).

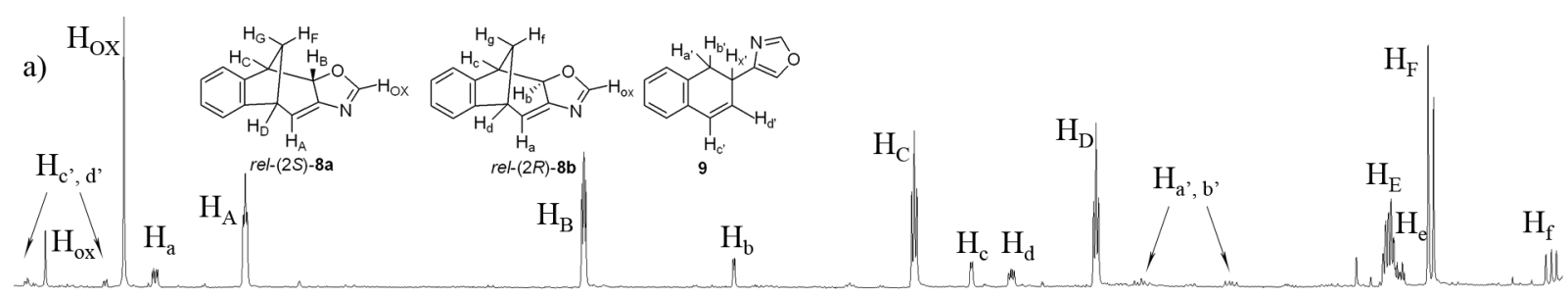

b)

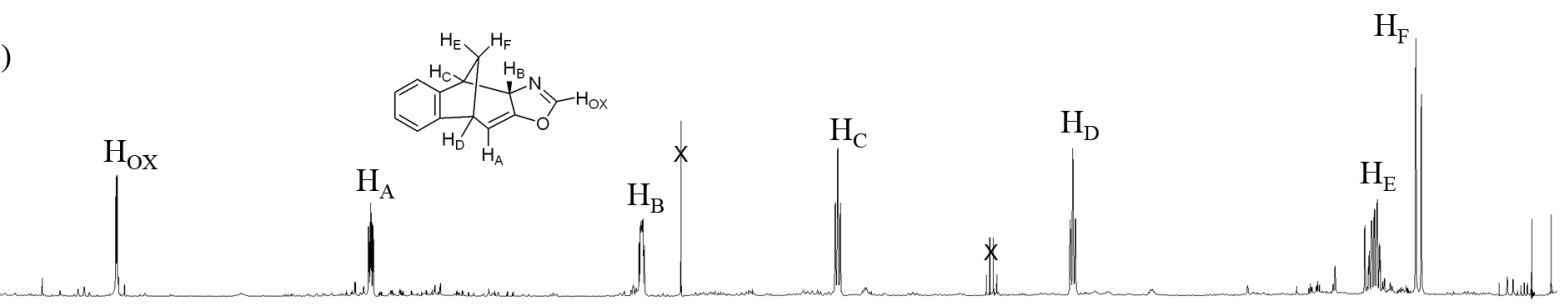


The structure of photoproduct $\mathbf{1 0}$ was completely determined using COSY, NOESY and HSQC techniques (see Supporting Information File 1). Aromatic protons of $\mathbf{1 0}$ are at 6.9-7.3 ppm and the proton on the oxazoline moiety is a singlet at $6.2 \mathrm{ppm}$. The specific aliphatic protons $\mathrm{H}_{\mathrm{A}}-\mathrm{H}_{\mathrm{F}}$ of the bicyclic skeleton (Figure 1) show a similar pattern as the previously described benzofuran intermediate [41]. In the ${ }^{13} \mathrm{C}$ NMR spectrum there are 5 signals in the region from 108 to $40 \mathrm{ppm}$. The doublet at $108 \mathrm{ppm}$ indicates the structure with $\mathrm{sp}^{2}$-hybridized carbon $\left(\mathrm{C}_{\mathrm{H}(\mathrm{A})}\right)$ and the triplet at $44 \mathrm{ppm}$ indicates the existence of one geminal carbon atom. The tetracyclic oxazoline stereoisomer rel-(2S)-10 undergoes spontaneously oxazoline ring-opening to 11 during the solvent evaporation after the irradiation and therefore the identification of this compound had to be done immediately after the work-up procedure. The formation of tricyclic formamido derivative rel-(9S)-11 can be explained by the addition of water to the exo-double bond of the bicyclic skeleton or the $\mathrm{C}=\mathrm{N}$ double bond and further oxazoline ring-opening (Scheme 3).

Formamido derivative $\mathrm{rel}-(9 S)-\mathbf{1 1}$ is completely characterized by spectroscopic methods. In its IR spectrum there are signals at $3334 \mathrm{~cm}^{-1}$ of the NH group, and strong signals at 1722 and $1683 \mathrm{~cm}^{-1}$ of two carbonyl groups. The formamido proton in the ${ }^{1} \mathrm{H}$ NMR spectrum appears at $8.29 \mathrm{ppm}$ and the proton of the NH group as a broad singlet at $6.29 \mathrm{ppm}$. Specific signals for the aliphatic protons $\mathrm{H}_{\mathrm{A}}-\mathrm{H}_{\mathrm{G}}$ of the benzobicyclo[3.2.1] octenone structure are present at higher field from 4.8 to $2.3 \mathrm{ppm}$ as expected (Figure 2: (b)). From the NOESY spectrum was evident that the $\mathrm{H}_{\mathrm{A}}$ is oriented towards the methano bridge.

The diastereomeric fused tetracyclic oxazolines rel-(2S)-8a and rel-(2R)-8b (Scheme 2, Figure 1), that were obtained on irradi-

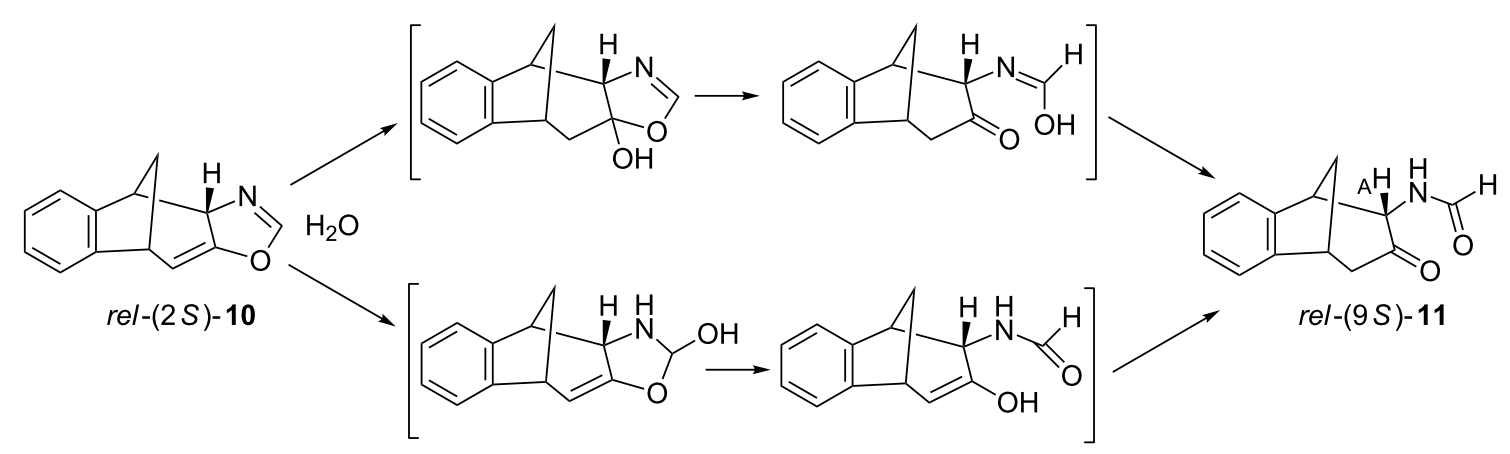

Scheme 3: Plausible mechanisms of oxazoline ring-opening in photoproduct 10.

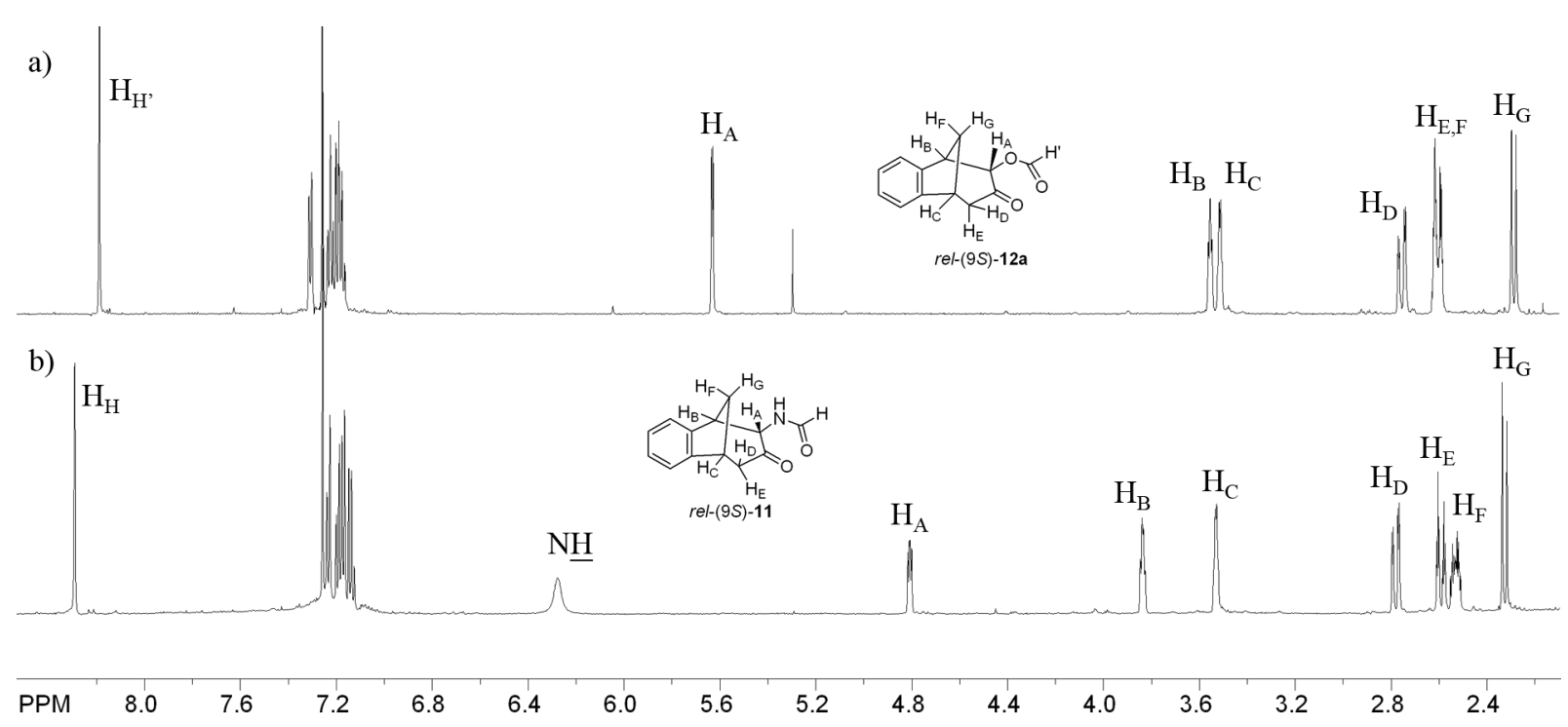

Figure 2: ${ }^{1} \mathrm{H}$ NMR spectra in $\mathrm{C}_{6} \mathrm{D}_{6}$ of rel-(9S)-12a (a) and rel-(9S)-11 (b). 
ation of cis/trans-4-(2-vinylstyryl)oxazole (1), are more stable than $\mathbf{1 0}$ but not sufficiently so that they can be separated chromatographically on silica gel. The major diastereomer 8a is isolated mixing the diastereomeric mixture for several hours in dry ether with some quantity of silica gel. The minor diastereomer $\mathbf{8 b}$ is identified and characterized in the NMR spectra of the photomixtures. The difference in structures of $\mathbf{8 a}$ and $\mathbf{8 b}$ is in the orientation of $\mathrm{H}_{\mathrm{B}}(\mathbf{8 a})$ or $\mathrm{H}_{\mathrm{b}}(\mathbf{8} \mathbf{b})$ protons. In the NOESY spectrum of the diastereomeric mixture the interaction between $\mathrm{H}_{\mathrm{B}}$ and $\mathrm{H}_{\mathrm{F}}$ protons can be seen which is a clear proof that the $\mathrm{H}_{\mathrm{B}}$ is facing the methano bridge in the major diastereomer 8a. There is no interaction between $\mathrm{H}_{b}$ and $\mathrm{H}_{\mathrm{f}}$ protons in the minor isomer $\mathbf{8 b}$ suggesting that $\mathrm{H}_{\mathrm{b}}$ proton is opposite to the methanobridge. The diastereomer in which the $\mathrm{H}_{\mathrm{B}}$ is oriented towards the methano bridge is the main product in photochemical reactions of either 4- or 5-(2-vinylstyryl)oxazole.

The formation of the photoproducts $\mathbf{8}$ and $\mathbf{1 0}$ can be explained by intramolecular cycloaddition and formation of resonance stabilized biradicals $\mathbf{A} / \mathbf{A}^{\prime}$ followed by the 1,6-ring closure (Scheme 4).

An 1,3-H shift, as in furan and thiophene derivatives [6], and rearomatization to fused oxazole derivatives $\mathbf{B} / \mathbf{B}$ ' is not detected. The 1,6-ring closure of the biradicals $\mathbf{A} / \mathbf{A}^{\prime}$ occurs stereoselectively giving the major products $\mathrm{rel}-(2 \mathrm{~S})-\mathbf{8} \mathbf{a} / \mathrm{rel}-(2 \mathrm{~S})$ 10 in which the hydrogen on $\mathrm{C}-2$ is oriented toward the methano bridge. The formation of dihydronaphthalene deriva- tive 9 , found only on irradiation of $\mathbf{1}$, is explained by $6 \pi$ electrocyclization of the benzodivinyl moiety to intermediate $\mathbf{C}$ followed by $1,5-\mathrm{H}$ shift and rearomatization of the benzene ring. Analogue electrocyclization was not detected in phenyl or furylsubstituted $o$-divinylbenzenes but instead stilbene-like $6 \pi$ electrocyclization and formation of 1-vinylphenanthrene [42] or 6-vinylnaphtho[2,1-b]thiophene [6] occured, respectively.

During chromatography on silica gel the tricyclic formiato derivative rel-(9S)-12 is formed from $\mathbf{8}$ (Scheme 5).

In the ${ }^{1} \mathrm{H}$ NMR spectrum the main diastereomer rel-(9S)-12a shows the signal of the formiato proton in the low field at $8.2 \mathrm{ppm}$. The signals from 5.6 to $2.3 \mathrm{ppm}$ are assigned to $\mathrm{H}_{\mathrm{A}}-\mathrm{H}_{\mathrm{G}}$ protons of the bicyclic skeleton. Using COSY and NOESY techniques all corresponding interactions are found. The signals of two carbonyl groups located at $200.8(\mathrm{C}=\mathrm{O})$ and $159.3\left(\mathrm{CH}^{\prime}=\mathrm{O}\right) \mathrm{ppm}$ in the ${ }^{13} \mathrm{C}$ NMR spectrum were confirmed in the IR spectrum with the bands at 1740 and $1714 \mathrm{~cm}^{-1}$. No signal for a NH proton was found in the ${ }^{1} \mathrm{H}$ NMR (Figure 2: (a)) nor the NH band in the IR spectrum. Its HRMS also confirmed the compound without the presence of nitrogen. The NOE interaction between protons $\mathrm{H}_{\mathrm{A}}$ and $\mathrm{H}_{\mathrm{G}}$ proved that the $\mathrm{H}_{\mathrm{A}}$ proton is facing to the methano bridge and that in the open structure rel(9S)-12a $\mathrm{H}_{\mathrm{A}}$ retained the same orientation as it had in the closed product 8a. ${ }^{1} \mathrm{H}$ NMR spectra of rel-(9S)-12a and rel-(9R)-12b are similar and have comparable interactions of protons in the COSY spectra. Unlike the NOESY spectrum of rel-(9S)-12a

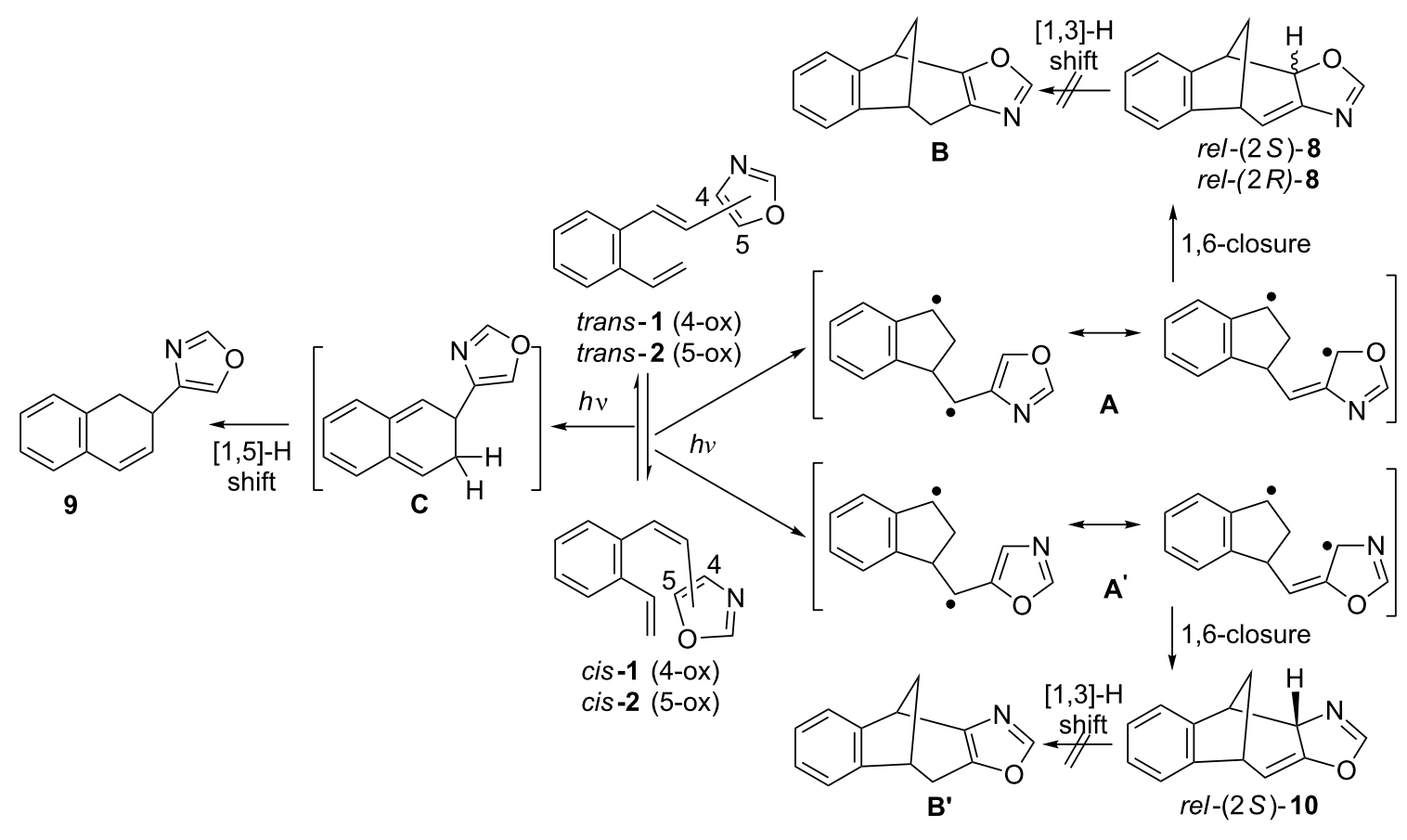

Scheme 4: Mechanism of the formation of polycyclic compounds (8-10). 


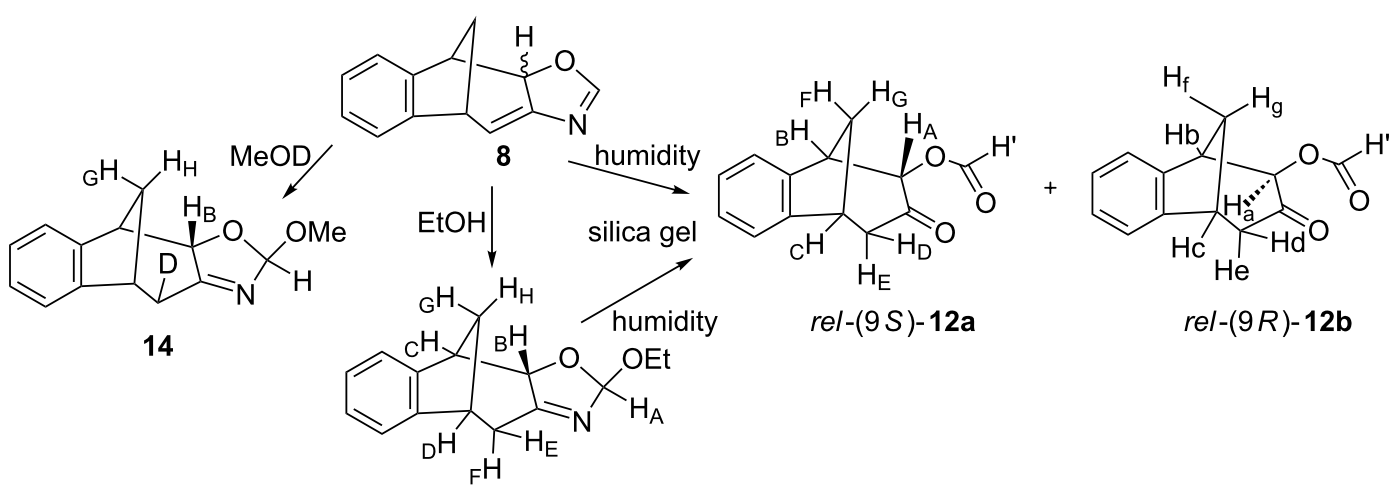

13

Scheme 5: Reactions of the photochemical product 8 with $\mathrm{EtOH}, \mathrm{MeOD}$ and $\mathrm{H}_{2} \mathrm{O} /$ silica gel.

with $\mathrm{H}_{\mathrm{A}}$ at $5.61 \mathrm{ppm}$ in interaction with $\mathrm{H}_{\mathrm{G}}$, the $\mathrm{H}_{\mathrm{a}}$ proton at $5.07 \mathrm{ppm}$ of rel-(9R)-12b has no interaction with $\mathrm{H}_{\mathrm{g}}$.

The photoproduct $\mathbf{8}$ is more stable than $\mathbf{1 0}$. The stability can be attributed to the existence of conjugated double bonds present in the structure. The structure of $\mathbf{8}$ in which the exo-double bond is in conjugation with the oxazoline double bond is also confirmed by isolation of adducts $\mathbf{1 3}$ and $\mathbf{1 4}$ (Scheme 5).

When the crude photomixture, containing $\mathbf{8 a}, \mathbf{8 b}$ and $\mathbf{9}$, was dissolved in absolute ethanol and left in a refrigerator at $13{ }^{\circ} \mathrm{C}$ over the weekend the adduct $\mathbf{1 3}$ was formed as a main product. The same procedure with MeOD showed the incorporation of deuterium in the bicyclo[3.2.1] octadiene moiety and a methoxy group on the $\mathrm{N}=\mathrm{C}$ oxazoline bond by 1,4 -addition or more likely by addition to the $\mathrm{N}=\mathrm{C}$ bond followed by keto-enol tautomerization giving $\mathbf{1 4}$. The adducts are spectroscopically completely identified (see Supporting Information File 1). The spectra of alcohol adducts show that alongside with $(2 S)-\mathbf{1 3} / \mathbf{1 4}$ there were traces of 9 and traces of what we suspect to be $(2 R)$ 13/14. Products $13 / 14$ easily undergo ring opening on silica gel giving the same formiato derivative 12. Plausible mechanism of the ring opening of oxazoline derivative $\mathbf{8}$ might be as outlined in Scheme 6.

\section{Conclusion}

In summary, photochemical fused oxazoline-benzobicyclo[3.2.1] octadiene products $\mathbf{8}$ and $\mathbf{1 0}$ are formed by photochemical intramolecular cycloaddition of 4- (1) and 5-(2-vinylstyryl)oxazoles (2), respectively. Product 10 spontaneously undergoes ring opening and formation of benzobicyclo[3.2.1] octenone derivative 11. Diastereomers 8 are stable under non-acidic conditions allowing the isolation of the main diastereomer 8a. They are easily hydrolyzed under mildly acidic conditions (silica gel) to functionalized benzobicyclo[3.2.1] octenone derivatives 12. Related benzobicyclo[3.2.1] octen-3-ones have been prepared by the method of Lansbury from chloroallylindene [43-45], by carbene reaction from benzonorbornadiene $[46,47]$ or by intramolecular insertion of the vinyl group into a carbon-carbon single bond using organometallic catalysts [48]. Herein we have reported a new simple method for the synthesis of functionalized benzobicyclo[3.2.1] octene derivatives using light as a traceless reagent [49].

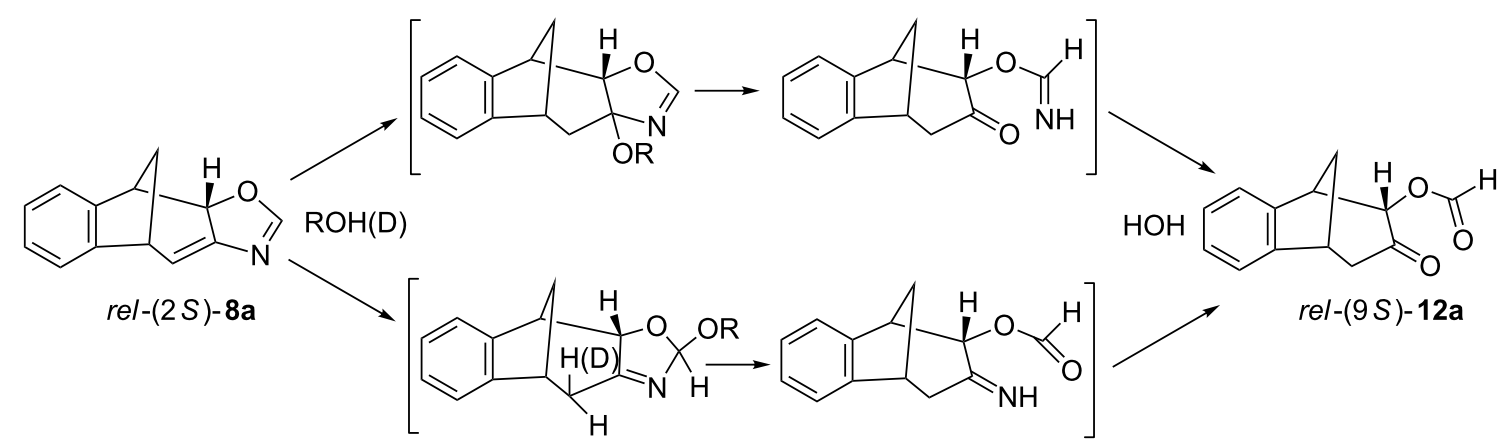

Scheme 6: Plausible mechanisms of oxazoline ring opening in photoproduct 10 and formation of 12. 


\section{Supporting Information}

\section{Supporting Information File 1}

Experimental part, NMR and IR spectra.

[http://www.beilstein-journals.org/bjoc/content/

supplementary/1860-5397-10-230-S1.pdf]

\section{Acknowledgements}

This work was supported by grants from the Ministry of Science, Education and Sports of the Republic of Croatia (grant no. 125-0982933-2926 and 098-0982929-2917).

\section{References}

1. Snyder, S. A.; Gollner, A.; Chiriac, M. I. Nature 2011, 474, 461-466. doi:10.1038/nature10197

2. Filippini, M.-H.; Rodriguez, J. Chem. Rev. 1999, 99, 27-76. doi:10.1021/cr970029u

3. Presset, M.; Coquerel, Y.; Rodriguez, J. Chem. Rev. 2013, 113, 525-595. doi:10.1021/cr200364p

4. Škorić, I.; Basarić, N.; Marinić, Ž.; Višnjevac, A.; Kojić-Prodić, B.; Šindler-Kulyk, M. Chem. - Eur. J. 2005, 11, 543-551. doi:10.1002/chem.200401005

5. Šindler-Kulyk, M.; Špoljarić, L.; Marinić, Ž. Heterocycles 1989, 29 , 679-682. doi:10.3987/COM-89-4629

6. Vidaković, D.; Škorić, I.; Horvat, M.; Marinić, Ž.; Šindler-Kulyk, M. Tetrahedron 2008, 64, 3928-3934. doi:10.1016/j.tet.2008.02.062

7. Vuk, D.; Marinić, Ž.; Molčanov, K.; Kojić-Prodić, B.; Šindler-Kulyk, M. Tetrahedron 2012, 68, 6873-6880. doi:10.1016/j.tet.2012.06.019

8. Vuk, D.; Marinić, Ž.; Molčanov, K.; Kojić-Prodić, B.; Šindler-Kulyk, M. Croat. Chem. Acta 2012, 85, 425-434. doi:10.5562/cca2120

9. Basarić, N.; Marinić, Ž.; Šindler-Kulyk, M. J. Org. Chem. 2006, 71, 9382-9392. doi:10.1021/jo061435t

10. Basarić, N.; Marinić, Ž.; Šindler-Kulyk, M. J. Org. Chem. 2003, 68, 7524-7527. doi:10.1021/jo0346454

11. Butković, K.; Basarić, N.; Lovreković, K.; Marinić, Ž.; Višnjevac, A.; Kojić-Prodić, B.; Šindler-Kulyk, M. Tetrahedron Lett. 2004, 45, 9057-9060. doi:10.1016/j.tetlet.2004.10.036

12. Butković, K.; Vuk, D.; Marinić, Ž.; Penić, J.; Šindler-Kulyk, M. Tetrahedron 2010, 66, 9356-9362. doi:10.1016/j.tet.2010.10.013

13. Butković, K.; Marinić, Ž.; Molčanov, K.; Kojić-Prodić, B.; Šindler-Kulyk, M. Beilstein J. Org. Chem. 2011, 7, 1663-1670. doi:10.3762/bjoc.7.196

14. Palmer, D. C. Oxazoles: Synthesis, Reactions, and Spectroscopy. In The Chemistry of heterocyclic compounds, Part A; Taylor, E. C.; Wipf, P., Eds.; John Wiley and Sons Inc.: New Jersey, 2003; pp 94-118.

15. Yeh, V. S. C. Tetrahedron 2004, 60, 11995-12042. doi:10.1016/j.tet.2004.10.001

16. Jin, Z. Nat. Prod. Rep. 2011, 28, 1143-1191. doi:10.1039/c0np00074d 17. Jin, Z. Nat. Prod. Rep. 2013, 30, 869-915. doi:10.1039/c3np70006b

18. Zhang, J.; Coqueron, P.-Y.; Vors, J.-P.; Ciufolini, M. A. Org. Lett. 2010, 12, 3942-3945. doi:10.1021/ol101704r

19. Zhang, J.; Ciufolini, M. A. Org. Lett. 2011, 13, 390-393. doi:10.1021/ol102678j

20. Zhang, J.; Ciufolini, M. A. Org. Lett. 2009, 11, 2389-2392. doi:10.1021/ol900455m
21. Cardwell, K. S.; Hermitage, S. A.; Sjolin, A. Tetrahedron Lett. 2000, 41, 4239-4242. doi:10.1016/S0040-4039(00)00573-6

22. Swaminathan, S.; Singh, A. K.; Li, W.-S.; Venit, J. J.; Natalie, K. J., Jr.; Simpson, J. H.; Weaver, R. E.; Silverberg, L. J. Tetrahedron Lett. 1998, 39, 4769-4772. doi:10.1016/S0040-4039(98)00904-6

23. Šagud, I.; Faraguna, F.; Marinić, Ž.; Šindler-Kulyk, M. J. Org. Chem. 2011, 76, 2904-2908. doi:10.1021/j01025942

24. Webb, M. R.; Addie, M. S.; Crawforth, C. M.; Dale, J. W.; Franci, X.; Pizzonero, M.; Donald, C.; Taylor, R. J. K. Tetrahedron 2008, 64, 4778-4791. doi:10.1016/j.tet.2008.01.116

25. Hoffman, T. J.; Rigby, J. H.; Arseniyadis, S.; Cossy, J. J. Org. Chem. 2008, 73, 2400-2403. doi:10.1021/jo702305g

26. Griesbeck, A. G.; Fiege, M.; Lex, J. J. Chem. Commun. 2000, 589-590. doi:10.1039/b000578i

27. Weuthen, M.; Scharf, H.-D.; Runsink, J. Chem. Ber. 1987, 120, 1023-1026. doi:10.1002/cber.19871200623

28. Griesbeck, A. G.; Bondock, S. Can. J. Chem. 2003, 81, 555-559. doi:10.1139/v03-029

29. Bondock, S.; Griesback, A. G. Monatsh. Chem. 2006, 137, 765-777. doi:10.1007/s00706-006-0474-4

30. Griesbeck, A. G.; Franke, M.; Neudörfl, J.; Kotaka, H. Beilstein J. Org. Chem. 2011, 7, 127-134. doi:10.3762/bjoc.7.18

31. Zhang, Y.; Wang, L.; Zhang, M.; Fun, H.-K.; Xu, J.-H. Org. Lett. 2004, 26, 4893-4895. doi:10.1021/ol048028t

32. Wang, L.; Huang, Y.-C.; Liu, Y.; Fun, H.-K.; Zhang, Y.; Xu, J.-H. J. Org. Chem. 2010, 75, 7757-7768. doi:10.1021/jo101764f

33. Šindler-Kulyk, M.; Stiplošek, Z.; Vojnović, D.; Metelko, B.; Marinić, Ž. Heterocycles 1991, 32, 2357-2363. doi:10.3987/COM-91-5846

34. Reeves, J. T.; Song, J. J.; Tan, Z.; Lee, H.; Yee, N. K.; Senanayake, C. H. Org. Lett. 2007, 9, 1875-1878. doi:10.1021/ol070340q

35. Mulder, R. J.; Shafer, C. M.; Molinski, T. F. J. Org. Chem. 1999, 64, 4995-4998. doi:10.1021/jo9906328

36. Addie, M. S.; Taylor, R. J. K. J. Chem. Soc., Perkin Trans. 12000 , 527-531. doi:10.1039/a908987j

37. Young, G. L.; Smith, S. A.; Taylor, R. J. K. Tetrahedron Lett. 2004, 45, 3797-3801. doi:10.1016/j.tetlet.2004.03.083

38. van Leusen, A. M.; Hoogenboom, B. E.; Siderius, H. Tetrahedron Lett. 1972, 13, 2369-2372. doi:10.1016/S0040-4039(01)85305-3

39. Saikachi, H.; Kitagawa, T.; Sasaki, H.; van Leusen, A. M. Chem. Pharm. Bull. 1979, 27, 793-796. doi:10.1248/cpb.27.793

40. Dale, W. J.; Starr, L.; Strobel, C. W. J. Org. Chem. 1961, 26, 2225-2227. doi:10.1021/jo01351a016

41. Škorić, I.; Basarić, N.; Marinić, Ž.; Šindler-Kulyk, M. Heterocycles 2001 55, 1889-1896. doi:10.3987/COM-01-9314

42. Šindler-Kulyk, M.; Laarhoven, W. H. Recl. Trav. Chim. Pays-Bas 1979, 98, 187-191. doi:10.1002/recl.19790980410

43. Lansbury, P. T.; Nienhouse, E. J. J. Am. Chem. Soc. 1966, 88, 4290-4291. doi:10.1021/ja00970a052

44. Lansbury, P. T.; Nienhouse, E. J.; Scharf, D. J.; Hilfiker, F. R. J. Am. Chem. Soc. 1970, 92, 5649-5657. doi:10.1021/ja00722a018

45. Wilt, J. W.; Rasmussen, R. R. J. Org. Chem. 1975, 40, 1031-1036. doi:10.1021/jo00896a007

46. Kitahonoki, K.; Takano, Y.; Matsura, A.; Kotera, K. Tetrahedron 1969, 25, 335-353. doi:10.1016/S0040-4020(01)82628-4

47. Balci, M.; Harmandar, M. Tetrahedron Lett. 1984, 25, 237-240. doi:10.1016/S0040-4039(00)99849-6

48. Murakami, M.; Itahashi, T.; Ito, Y. J. Am. Chem. Soc. 2002, 124, 13976-13977. doi:10.1021/ja021062n 
49. Hoffmann, N. Photochem. Photobiol. Sci. 2012, 11, 1613-1641. doi:10.1039/c2pp25074h

\section{License and Terms}

This is an Open Access article under the terms of the Creative Commons Attribution License

(http://creativecommons.org/licenses/by/2.0), which permits unrestricted use, distribution, and reproduction in any medium, provided the original work is properly cited.

The license is subject to the Beilstein Journal of Organic Chemistry terms and conditions:

(http://www.beilstein-journals.org/bjoc)

The definitive version of this article is the electronic one which can be found at:

doi:10.3762/bjoc. 10.230 